\title{
MISCELLANEA
}

\section{Association of Industrial Medical Officers: 21st Anniversary Meeting}

The Association of Industrial Medical Officers celebrated the twenty-first anniversary of its foundation by holding an Anniversary Meeting in London from September 24 to 28,1956 . The scientific sessions of the meeting were held at the London School of Hygiene and Tropical Medicine. The papers and subsequent discussions will be fully reported in the Transactions of the Association of Industrial Medical Officers.

At a reception given by the London Group, the President of the Association, Dr. R. S. F. Schilling, was invested by Sir Wilson Jameson with the new jewel. The central feature of the presidential jewel is a portrait, in enamel and gold, of Charles Turner Thackrah. Past presidents of the Association were presented with miniature replicas of the jewel. Sir Wilson Jameson spoke of the early days of the Association and recalled that he had encouraged its formation when he was consulted by a small group of industrial medical officers. He had advised them to avoid medical politics and to develop on a professional and social basis. He believed that the success of the Association had resulted from the adoption of this policy.

The inaugural meeting was opened by Mr. Iain MacLeod, Minister of Labour and National Service. The Minister referred to the great progress which had been made in the development of industrial medicine, supported by the growth of the Association and by the many doctors who were serving in industry on a parttime or whole-time basis. Like his predecessors, he was actively interested in furthering these developments. Several members of the Association were also members of his recently appointed Industrial Health Advisory Committee. He had initiated two pilot surveys of industrial health, a general survey in Halifax and the other concerned with the pottery industry and centred on Stoke-on-Trent. In his Presidential Address, Dr. Schilling outlined the development and activities of the Association and referred to the recent publication by the Association of a booklet on the functions of an occupational health service.* He hoped that this booklet would be found useful both by managements and by doctors newly entering the field of occupational health.

Professor Sven Forssman described his experience of the health problems of the older workers in Swedish industry. He had undertaken a study in eight industries

* The Functions of an Occupational Health Service in an Industrial Organization, published by the Association of Industrial Medical Officers, London, 1956 with 20,000 employees. Regular examinations were important, and were becoming increasingly so as the number of older people in the population increased. This social development was characteristic of countries with a high living standard. The increase of mechanization in industry was reducing the number of jobs requiring physical strength and might be expected to benefit the older workers, but they found it difficult to work at high speeds. There appeared to be two main groups of elderly workers: those who are in good health and those who had survived such illnesses as tuberculosis and diabetes because of improvements in medical treatment. Professor Forssman found that most employees over the usual retirement ages wished to continue at work. This was unrelated to pension rights and applied to both manual and clerical workers. Diseases of the circulatory system and of the organs of movements were the main causes of impaired health and working capacity of older workers. As has been found in other studies, older employees experienced more sickness absence than younger workers, particularly those employed on light work. The productivity of the older worker compared favourably with that of the average of workers as a whole. It was a mistake to put young and elderly employees to work together, because of their different speeds of work. Older workers should have longer midday breaks and rest pauses. The age of retirement should not be fixed but should be flexible and according to individual capacities.

The Mackenzie Industrial Health Lecture, sponsored by the British Medical Association, was delivered by Dr. R. S. F. Schilling. He said that the industrial medical officer was nowadays called upon to assess many physical and environmental factors concerning workpeople, and not merely to confine himself to the study of industrial disease. The methods of epidemiology were of much value in measuring hazards by comparing different occupational groups. Dr. Schilling referred to the work undertaken by Greenhow almost a century ago on mortality and morbidity rates. Recent research on coronary artery disease had shown that workers in physically active occupations experienced relatively less coronary disease than sedentary workers. An excess mortality of strippers and grinders in the cotton industry from cardiovascular-renal disease had been demonstrated. Statistics of sickness absence were essential for the study of morbidity but their use required considerable care, for they could be misleading as absence recorded as due to sickness did not always depend on pathology. Field surveys were of the greatest importance in the study of industrial disease, but their success depended on the cooperation of the population concerned. Observer errors in clinical and radiological signs were also very important. 
At a symposium-discussion on " Research in Occupational Health" the chair was taken by Dr. M. W. Goldblatt. The Earl of Verulam suggested that occupations might be classified as sedentary, peripatetic, peculiar, asymmetrical, or mobile. More research was needed into problems of seating and posture at work. Industry was not opposed to research, or to the application of knowledge acquired by research. There was likely to be a growing demand for steadily rising standards of working conditions. Sir Harold Himsworth, speaking on "The Relating of Research to Practice ", said that the separation between fundamental and applied research was essentially artificial. Progress depended on the smooth flow of ideas from one to the other. Unfortunately, workers at these two extremes tended to be widely apart in their ideas. There was need for a continuous chain of men with overlapping skills and experience, from the laboratory to the field. It was inadequate simply to mix men with the two different skills. Sir Alfred Roberts stressed the need for a comprehensive occupational health service which underlay all aspects of occupational health, including research. The essential requirements were a coordinated Government policy and a substantial increase in the resources devoted to occupational health. In providing additional resources consideration should be given to the establishment of an industrial hygiene service to assess environmental conditions and tackle the problem of occupational health risks arising from the introduction of new materials and processes. It was essential that field investigations should occupy a large part of any programme of occupational health research.

Dr. Katharine Williams read a paper on " The Impact on Medicine and Industry of the Use of Atomic Energy ". The demands of nuclear engineering had resulted in the development of new materials; high temperatures and intense radiations called for research and development in metallurgy. Radiations from reactors and isotopes could alter the physical properties of materials such as polythene. Radiation-induced sterilization could be used for the preservation of foodstuffs and for pharmaceutical and medical supplies.

The film "Calder Hall " was shown by Dr. Williams during this lecture.

A lecture-demonstration on "Weight-Handling " was given by Mr. R. J. McD. Maxwell. After an introductory talk on "cumulative strain" (as opposed to traumatic strain) Mr. Maxwell described six key factors in the technique of kinetic handling, viz., proper hold, proper foot positions, straight back, arms into sides, chin in, and counterbalance. A demonstration of the different movements involved in handling boxes, bags, barrels, and other objects followed.

Professor R. E. Lane delivered the John C. Bridge Memorial Lecture on "The Place of Occupational Medicine in a Teaching Hospital ". He suggested that an occupational medicine unit improved the hospital service to patients, broadened medical teaching, and contributed to clinical research. Professor Lane described the work undertaken by his department at Manchester Royal Infirmary during the three-year period 1953-55. There were 511 new male patients, 177 of whom were suffering from chronic respiratory disease (including pneumoconiosis and byssinosis) and 44 were suffering from other industrial diseases. The lecture was illustrated with nine case histories, demonstrating the need for the hospital physician to gain a knowledge of the working conditions and social and economic circumstances of his patients. The resettlement of 180 men in industry was described; 18 months after resettlement $47 \%$ of these men remained settled in suitable work, $23 \%$ were not working and $28 \%$ could not be traced. The place of occupational health in undergraduate medical teaching was discussed. Clinical teachers should show the student how work can heal as well as harm; too often it is only the harmful effects of work that receive mention. Direct teaching should be undertaken at the occupational medicine clinic, where medico-social problems, including the patient's occupation, are dealt with as part of the whole clinical problem. Professor Lane emphasized the contribution to clinical research which could be made by the department of occupational medicine, quoting the work undertaken in his department on byssinosis and poisoning by cadmium fumes.

At the session on "Mental Health in Industry" the chair was taken by Dr. L. G. Norman. Dr. R. F. Tredgold spoke on "The Use of Psychiatry in Management Training Problems". He said that there had been a great increase in formal management training programmes, most of which emphasized the need to understand the individual worker. Hence many firms incorporated teaching in psychiatry, either openly or camouflaged, in such programmes. Dr. Tredgold outlined the techniques which could best be used by the psychiatrist when taking part in management training and emphasized the need for the psychiatrist to be in close touch with the working environment and with the latest research. Dr. Alastair Heron read a paper on " Psychological Research in Industry " in which he perceived the rôle of the psychologist as that of an enquirer whose relatively objective findings might be found useful by such potential consumers as the industrial manager and his medical and personnel advisers. His enquiries should concern persons as individuals: the relations between persons; and those between persons and machines. The research psychologist should devote considerable attention to methods of training and he should always study employee satisfaction as well as individual efficiency. The adaptation of the marginal employee would always constitute a major challenge to the research psychologist in the occupational field. A paper on "Work, Payment, and Capacity" was given by Dr. Elliott Jaques, in which results were presented to show that level of work, or level of responsibility in jobs could be accurately measured. Measurement was based on the assessment of the maximum span of time during which an employee was expected to exercise discretion on his own account without review. This time-span measure could be applied to any job from shop floor to top executive level. Peace of mind for the individual in his work required that he be allocated a level of work that was consistent with his capacity and which kept pace with his growth in capacity; and that he be paid at a level consistent with the current time-span payment scale. Deviations from a consistent relationship between the individual's work, payment, and capacity 
produced behavioural symptoms which could be predicted. Examples of such patterns of behaviour were described.

During the week visits were paid to a number of industrial organizations in the London area and there was a full social programme for members and their wives.

An exhibition of the medical services of the Ministry of Supply was open during the week at the Pillar Hall in the new Government buildings, Whitehall. Exhibits and illustrations were shown, covering many types of hazards and the protection required. Of particular interest was the resuscitation section in which the historical development of resuscitation procedures was illustrated with examples of old and modern types of equipment.

The anniversary dinner was held at the Royal College of Surgeons on the anniversary date, September 27, of the foundation of the Association 21 years before. The toast of the Association was proposed by Sir Harry Platt, who spoke of the need for all branches of medicine to work together. The President of the Association, Dr. R. S. F. Schilling, in his reply, foresaw a steadily developing future for occupational health services, bringing great benefit to industry. In proposing the toast of "Medicine in Industry" the Earl of Verulam recalled the many benefits to industrial management which an occupational health service provided. The toast of the guests was proposed by Dr. L. G. Norman, and Dame Florence Hancock replied.

\section{Erratum}

We much regret that the legends to the paper by J. N. Morris in the last number $(13,287)$ were omitted. They are as follows:-

Fig. 1.-Mortality in the "social classes" England and Wales, 1950. Males aged 20-64 inclusive.

FIG. 2.-Mortality from coronary heart disease England and Wales, 1950. Males aged 20-64 years inclusive.

\section{Industrial Medicine and Hygiene}

\author{
A Review by \\ L. G. NORMAN
}

This is the only book in the English language which brings together a series of authoritative essays comprehensively covering almost the whole field of industrial medicine and hygiene. Messrs. Butterworth \& Company are to be congratulated on their foresight and enthusiasm, no doubt stimulated by the late Lord Horder, in developing this work. Dr. E. R. A. Merewether, as Editor, has not only achieved a personal masterpiece; he has placed British industrial medicine firmly in the forefront. To collate the balanced contributions of 33 individualistic experts, to make them speak roughly the same language, and avoid overlapping each other's contributions to any serious extent is a remarkable achievement. It has been a task which few would care to undertake and the three present volumes will remain a lasting tribute. There is indeed a galaxy of authors, each at the head of the field about which he writes. The work is perhaps least strong on the clinical side, but it does not set out to be a clinical text-book, and about half the authors, leaders in their own field, are not medical men. There are one or two omissions, which, together with a summary of recent advances, will, it is hoped, form the basis of a further volume or volumes in order that the book as a whole may be kept up to date. For example, there is little about the treatment of gassing casualties, humanengineering aspects of machine design, the clinical aspects of toxicology, accident prevention, the effects of shift work, and psychiatry in industry.

There is a good index, separate for each volume. The production is of a high standard throughout, on good quality art paper, with excellent illustrations, and with a refreshing absence of typographical errors.

\section{Volume I}

This volume was published in 1954 and is inevitably out of date in minor respects. It is interesting to note that progress seems to have been most marked in legislation. For example, the Mines and Quarries Act and the Food and Drugs Act, 1955 (and Regulations), have been passed since the relevant chapters in this volume were written.

The volume opens formidably but perhaps appropriately with an account of the work of the Factory Inspectorate by H.M. Chief Inspector of Factories. Sir George Barnett's brief and impeccable first chapter describes the history of the Factory Inspectorate and gives an account of its present-day activities. As this is

Industrial Medicine and Hygiene. Vols. 1-3. Edited by E. R. A. Merewether. (Pp. ix +426 , vi +451 , vii +617 respectively; illustrated. 70s. per volume; 10 gns. per set.) London, Butterworth Medical Publications: 1956. 